Original Research Paper

\title{
Evaluation of Anthelmintics Resistance Against Gastrointestinal Parasites Infection in Awassi Sheep in Jordan and The use of Alternative Herbal Anthelmentics
}

\author{
Firas Mahmoud Hayajneh, Hosam Hani Titi, Mufeed Awni Alnimer and Rabie Irshaid \\ Department of Animal Production, The University of Jordan, Amman 11942, Jordan
}

\author{
Article history \\ Received: 17-12-2018 \\ Revised: 30-04-2019 \\ Accepted: 10-05-2019 \\ Corresponding Author: \\ Firas Mahmoud Hayajneh \\ Department of Animal \\ Production, The University of \\ Jordan, Amman 11942, Jordan \\ Tel: (Mobile) +962778486050 \\ (fixed) +96265355000 , ext. \\ 22465, Fax: +96265300806.05- \\ 03-201928-03-2019 \\ E-mail: F_hayajneh @ju.edu.jo
}

\begin{abstract}
This study aimed to uncover the prevalence of anthelmintic resistance in ovine gastrointestinal nematodes in middle and north Jordan and to check the in vivo anthelmintic efficacy of apple cider vinegar drench and ginger powder. For this purpose a parasitological study was designed, which used fecal egg count reduction test Two hundred seventy ewes were enrolled in this study, twenty sheep farms were enrolled in this study, which had concerns about anthelmintic efficacy. On each farm, 10 sheep were randomly allocated to one of six treatment groups and five for an untreated control group. Fecal samples were collected on day 0 and days 10-14 for worm egg counts and larval differentiation at 6:00 am at the time of milking. Based on the morphometric identification of larvae, Trichostrongylous $85 \%$ was the predominant species, Oestertagia $10 \%$ and Haemonchous 5\%. There was resistant against all species in the used anthelmintic drug, the highest reduction was noticed in the Ivermectin group and the lowest reduction rate was noticed in albendazole groups. There was low resistance against ginger powder and apple cider vinegar which means that they have a strong anthelmintic effect against gastrointestinal parasites.
\end{abstract}

Keywords: Anthelmentic, Resistance, Ginger, Sheep, Parasites, Trichostongylous

\section{Introduction}

Effective anthelmintics are needed for the implementation of integrated parasite control programs, which combine nonpharmacological methods with strategic use of drugs, Monitoring of Fecal Egg Count (FEC), the evaluation of treatment efficacy and the detection of Anthelmintic Resistance (AR) are becoming increasingly important for health programs of grazing livestock (Pena-Espinoza et al., 2014). Anthelmintic Resistance (AR) in gastrointestinal nematodes (GINs) has been reported worldwide (Rose et al., 2015).

Increasing problems of anthelmentic resistance development which is associated with conventional production systems, which are more reliant on the use of antiparasitic drugs, but less in organic systems, where the prophylactic use of anthelmintics is banned (Hoste et al., 2014), led to the proposal of checking medicinal plants for their anthelmintic activity. Resistance against synthetic anthelmintics for gastrointestinal parasites is a worldwide problem of sheep and goat (Urban et al., 2008; Yashaswini et al.,
2016). Haemonchus contortus was the first nematode to develop resistance against the different anthelmintics. The first report of decreased efficacy of thiabendazole against $H$. contortus was just 3 years after its introduction to the market (Verma et al., 2018), anthelmintic resistance has been reported in number of countries (Hamdullah et al., 2015).

This had led farmers to search for alternatives that include the use of medicinal plants to treat and control livestock parasites. There is also some belief that herbal products are safe to use and harmonious with the biological system (Sanhokwe et al., 2016). larger number of plants naturally available possess narrow or broad spectrum anthelmintic activities. For both developed and less developed countries, recognition and development of herbal medicine offer treatment methods that are more environmentally benign apparently do not trigger anthelmintic chemoresistance (Sujon et al., 2008).

Zingiber officinale, known as ginger, belonging to the family Zingiberaceae is a familiar spice, which has several medicinal properties. It has been widely used as a 
common household remedy from ancient times (Nandi et al., 2013). The crude extract and the essential oil of Zingiber officinale contains important constituents, which are responsible for anti-inflammatory, antidiarrheal, antibacterial, antiviral, antifungal, spasmolytic action and antioxidant properties (Jeena et al., 2013). Iqbal (2006) demonstrated in vivo anthelmintic activity of ginger against gastrointestinal nematodes of sheep, El-Bahy and Bazh (2015) evaluated the anthelminitic activity of ginger on the cestode Raillietina cesticillus. Lin et al. (2014) suggested that constituents of ginger might be used as cestocidal agents against $H$. nana. According to Hayajneh et al. (2018), doses of natural apple cider vinegar administered in drinking water have shown anticoccidial effects against Eimeria species.

In this study, four commonly used anthelmintics (Spectrazole $\left(\mathrm{T}_{\mathrm{SPEC}}\right)$, Fenbendazole $\left(\mathrm{T}_{\mathrm{FEN}}\right)$, Ivermectin $\left(\mathrm{T}_{\mathrm{IVR}}\right)$, Albendazole $\left(\mathrm{T}_{\mathrm{ALB}}\right)$, resistance is being measured and compared with apple cider vinegar drench and ginger powder $)$, apple cider vinegar $\left(\mathrm{T}_{\mathrm{ACV}}\right)$ and Ginger powder $\left(\mathrm{T}_{\mathrm{GN}}\right)$.added to ration.

\section{Materials and Methods}

\section{Study Place}

This research was conducted in different farms in different places in northern and middle part of Jordan; we enrolled 20 farms for Anthelmintic Resistance (AR) testing from July 2017 to June 2018. Testing targeted farmers that complained of treatment failure by ministry of agriculture and private veterinary clinics in Jordan.

\section{Animals}

Two hundred seventy ewes were enrolled in this study, 20 farms in different parts in Jordan were enrolled for testing AR, 10 female sheep on each farm were randomly allocated to one of six treatment groups (with Spectrazole $\left(\mathrm{T}_{\mathrm{SPEC}}\right)$, Fenbendazole $\left(\mathrm{T}_{\mathrm{FEN}}\right)$, Ivermectin $\left(\mathrm{T}_{\mathrm{IVR}}\right)$, Albendazole $\left(\mathrm{T}_{\mathrm{ALB}}\right)$, apple cider vinegar $\left(\mathrm{T}_{\mathrm{ACV}}\right)$ and Ginger powder $\left(\mathrm{T}_{\mathrm{GN}}\right)$ and untreated control group. Fecal samples were collected on day 0 and days 10-14 for worm egg counts and larval differentiation. Animals used in this experiment were of ages ranging (16-36 months old) and were not treated for gastrointestinal parasites for a minimum of 60 days prior to the study. Animals were distributed so that the mean Eggs Per Gram (EPG) were similar among groups. Weight of animals was recorded before starting of the treatment to adjust for the correct dose according to the manufacturer recommendations. Apple cider vinegar was prepared according to Hayajneh et al. (2015). The apple cider vinegar was chemically analyzed and its $\mathrm{pH}$, density and content of organic acids were evaluated before administrating it to the chickens. The $\mathrm{pH}$ of apple cider vinegar was evaluated to be 2.5 , density was $1.02 \mathrm{grams} / \mathrm{ml}$; whereas the content of organic acids were within normal limits. A daily dose of $5 \mathrm{ml} /$ animal diluted in water repeated three times (reference) was used in this study.

\section{Ginger Powder}

Ginger powder was purchased from local market and added in ration at level (0.1\%) (Tag el-din et al., 2012), the ration was used for two weeks.

\section{Experimental Design}

According to the following: Ivermectin $\left(\mathrm{T}_{\mathrm{IVR}}\right) 1 \%$ $0.2 \mathrm{mg} / \mathrm{kg}$ body weight $\mathrm{kg}, \mathrm{T}_{\mathrm{a}}$ : Albendazole $\left(\mathrm{T}_{\mathrm{ALB}}\right)$ $25 \% 5 \mathrm{mg} / \mathrm{kg}$, Fenbendazole $\left(\mathrm{T}_{\mathrm{FEN}}\right), 10 \% 5 \mathrm{mg} / \mathrm{kg}$, Spectrazole $\left(\mathrm{T}_{\mathrm{SPEC}}\right)$, Ginger powder $\left(\mathrm{T}_{\mathrm{GN}}\right)$, apple cider vinegar $\left(\mathrm{T}_{\mathrm{ACV}}\right)$ and $\mathrm{T}_{\mathrm{c}}$ : Control group that received no treatment. Doses were given according to drug manufacturer instructions. Fecal samples were collected directly from the rectum at day 0 (pretreatment) and at days 10-14 at 6:00 Am at the time of milking where all animals are present at one place.

\section{Detection of AR in Vivo}

Fecal Egg Count Reduction Test (FECRT) was used to determine Anthelmintic Resistance (AR). Predrench (day 0) and post-drench (days 10-14) Fecal Egg Counts (FEC) and Larval Differentiation (LD) to different genera were used in the calculation of AR. On each farm, groups of 10 sheep were randomized to treatment groups $(\mathrm{n}=10)$ and a corresponding untreated control group. Allocation of sheep into groups was done by numbered and colored ear tags applied on day 0. Six treatments were tested; two anthelmintics were tested on each farm. tested anthelmintics are shown in Table 1.

Table 1: Anthelmintics tested in sheep in Jordan

\begin{tabular}{|c|c|c|c|c|}
\hline Dose & Length of action & Active ingredient & $\begin{array}{l}\text { Dose rate/body } \\
\text { weight }\end{array}$ & $\begin{array}{l}\text { Administration } \\
\text { route }\end{array}$ \\
\hline Single & Short & Ivermectin & $2.5 \mathrm{ml} / 10 \mathrm{~kg}$ & Injection \\
\hline Single & Short & Albendazole & $3 \mathrm{ml} / 10 \mathrm{~kg}$ & Oral \\
\hline Single & Short & Spectrazole Albenda+levamisole) & $1 \mathrm{ml} / 10 \mathrm{~kg}$ & Oral \\
\hline Single & Short & Fenbendazole & $3 \mathrm{ml} / 10 \mathrm{~kg}$ & Oral \\
\hline Multiple & Long & Apple cider vinegar & 5l/animal, 3 doses & Oral \\
\hline Multiple & Long & Ginger powder & $0.1 \%$ In ration/ 2 weeks & Oral \\
\hline
\end{tabular}




\section{Parasitology}

Samples were analyzed by the modified McMaster technique. Eggs were counted at $\times 40$ magnification with 1 egg equivalent to 40 eggs of faces. Larval cultures were set up for each group, incubated for 7 days at $27^{\circ} \mathrm{C}$. Differentiations of at least 100 infective larvae (L3) were done for each culture (Lyndal-Murphy et al., 2014).

\section{Determination of Anthelmintic Resistance (AR)}

In February 2017 preliminary FECs of a group of untreated sheep (age-36 months) at the study area revealed a mean egg count of ( \pm 3732$)$ Eggs Per Gram (EPG) of faeces. Pre-and post-drench differentiated fecal egg counts from both treated and untreated groups of sheep were used in the calculation of AR and to control continuous larval development during the test evaluation period.

For the Fecal Egg Count Reduction Test (FECRT), the calculations to estimate the percentage mean reduction of egg counts with $95 \%$ confidence intervals were performed in an Excel spreadsheet made by Angus Cameron (Aus Vet Animal Health Services for the University of Sydney). Calculations were based on the RESOC FECRT analysis program (Version 2.0 CSIRO, Animal Health Research Laboratory, PARKSVILLE, 3052, University of Sydney). Resistance to an anthelmintic class occurs when the percentage reduction in EPG after treatment is less than $95 \%$ and the lower limit of the $95 \%$ confidence interval is less than $90 \%$. according to the World Association for the Advancement of Veterinary Parasitology guidelines

When one of these two criteria is met, AH resistance is suspected. Recently, the inclusion of the upper $95 \%$ confidence limit in the assessment of the anthelmintic resistance status was recommended because with this inclusion, the situations in which anthelmintic resistance is possible but not certain can be distinguished from those in which anthelmintic resistance is confirmed (Alcalá Canto et al., 2016).

\section{Statistical Analysis}

Data analysis was done $u$ using a spreadsheet created by Angus Cameron, AusVet Animal Health Services for the University of Sydney. Calculations are based on those of the 'Reso' FECRT analysis program (Version 2.0Revised 17-07-90) by Leo Wursthorn and Paul Martin of CSIRO, Animal Health Research Laboratory, PARKVILLE, 3052. Calculations are based on those published in 'Anthelmintic Resistance': Report of the Working Party for the Animal Health Committee of the SCA. CSIRO, 1989.

\section{Results}

As shown in Table 2 the most effective anthelmentic used against all species was Ivermectin (FECR $=91 \%$ ), ginger powder in ration, apple cider drench had shown strong reduction for internal parasite counts $(\mathrm{FECR}=$ 91,88 respectively), Based on the morphometric identification of larvae, Trichostrongylous $85 \%$ was the predominant species, Oestertagia 10\% and Haemonchous $5 \%$. Trichostongylous spp were the most common gastrointestinal parasites used and has shown resistance against all used anthelmentics, there was low resistance against apple cider vinegar and ginger powder (Table 2).

\section{Discussion}

In this study anthelmintic resistance is present against all anthelmentics under investigation (Ivermectin, Albendazole, Spectrazole Albendazol, levamisole and Fenbendazole where FECR is less than $95 \%$ for all anthelmintic used, these results agree with early reports from Denmark indicating reduced field efficacy of BZ and IVM in sheep and goat farms (PenaEspinoza et al., 2014; Sherrill et al., 2006), Nielson (2012) demonstrated resistance in $H$. contortus resistance to MOX ( $74 \%$ of farms), CLOS ( $77 \%$ of farms) and LEV (57\% of farms), ivermectin has the highest FECR ratio which was $84 \%$ against all species. Apple cider vinegar and ginger powder had shown high FECR ratio $(88 \%, 91 \%)$ but had shown low resistance (Table 2), these results agree with the results shown by Mahmoud et al. (2014) who demonstrated that ginger caused reduction of fecal cyst and trophozoites counts.

Table 2: Marginal means and 95\% CIs of the percent reduction of eggs per gram at 14 and 21 days after treatment of sheep $(n=10$ per flock) with Spectrazole $\left(\mathrm{T}_{\mathrm{SPEC}}\right)$, Fenbendazole $\left(\mathrm{T}_{\mathrm{FEN}}\right)$, Ivermectin $\left(\mathrm{T}_{\mathrm{IVR}}\right)$, Albendazole $\left(\mathrm{T}_{\mathrm{ALB}}\right)$, apple cider vinegar $\left(\mathrm{T}_{\mathrm{ACV}}\right)$ and Ginger powder $\left(\mathrm{T}_{\mathrm{GN}}\right)$

\begin{tabular}{|c|c|c|c|c|c|c|c|c|}
\hline Drench & Pre-Test & Control & $\mathrm{T}_{\text {SPEC }}$ & $\mathrm{T}_{\mathrm{FEN}}$ & $\mathrm{T}_{\mathrm{IVR}}$ & $\mathrm{T}_{\mathrm{ALB}}$ & $\mathrm{T}_{\mathrm{ACV}}$ & $\mathrm{T}_{\mathrm{GN}}$ \\
\hline Arith. Mean & 6275 & 5970 & 3709 & 4990 & 959 & 2389 & 739 & 562 \\
\hline Var (FEC) & 946114 & 805088 & 1614602 & 274126 & 4272193 & 9822213 & 35663 & 16109 \\
\hline$\%$ Reduction & & & 38 & 16 & 84 & 60 & 88 & 91 \\
\hline Upper 95\% CL & & & 48 & 23 & 94 & 78 & 89 & 92 \\
\hline Lower 95\% CL & & & 26 & 9 & 56 & 26 & 86 & 89 \\
\hline Drench effectiveness & & & Resistant & Resistant & Resistant & Resistant & Resistant $\mathrm{t}^{\mathrm{a}}$ & Resistant $^{a}$ \\
\hline
\end{tabular}

a: low resistance, FEC: Fecal Egg Count 
Histopathology, Scanning Electron Microscopy (SEM) and Transmission Electron Microscopy (TEM) after exposure to each extract revealed evident improvement of intestinal mucosal damage produced by G. lamblia infection and direct structural injury to the trophozoites, Hayajnehn (2018) demonstrated that ginger has anticoccidial activity against coccidiosis in broilers, also vinegar has been used in a trial to reduce infectivity of cysticercal cysts and the larvicidal effect was attributed to the acetic acid content (Zanini and Graeff-Teixeira, 2001), Sadjjadi (2008) demonstrated that vinegar has giardiacidal activity, Hayajneh et al. (2018) also proved anticoccidial effect of apple cider vinegar against coccidiosis in broilers. Rahmann and Seip, (2006) demonstrated that a mixtures of Plants containing apple cider vinegar and garlic can be used as an alternative de-wormers.

\section{Conclusion}

Apple cider vinegar drench and ginger powder added to ration have an anthelmintic effect almost equal to that of the strongest anthelmintic used, these herbs could be used to treat and prevent gastrointestinal parasitism and these herbs are safe for human consumers. The present study proved the effectiveness of ginger powder and apple cider vinegar as promising natural therapeutic agents against gastrointestinal parasites in sheep.

\section{Acknowledgment}

The author wants to thank the University of Jordan for the financial support.

\section{Ethics}

This article is original and contains unpublished material. The corresponding author confirms that all of the other authors have read and approved the manuscript and no ethical issues involved.

\section{References}

Alcalá Canto, Y., H.S. Sumano Lpez, L. Ocampo Camberos and L. Gutiérrez, 2016. Anthelmintic resistance status of gastrointestinal nematodes of sheep to the single or combined administration of benzimidazoles and closantel in three localities in Mexico. Vet. México OA..

DOI: 10.21753/vmoa.3.4.374

El-Bahy, N.M. and E.K. Bazh, 2015. Anthelmintic activity of ginger, curcumin and praziquentel against Raillietina cesticillus (in vitro and in vivo). Parasitol Res., 114: 2427-34.

DOI: $10.1007 / \mathrm{s} 00436-015-4416-0$
Fleming, S.A., T. Craig, R.M. Kaplan, J.E. Miller and C. Navarre et al., 2006. Anthelmintic resistance of gastrointestinal parasites in small ruminants. J. Vet. Int. Med., 20: 435-444.

DOI: $10.1111 / \mathrm{j} .1939-1676.2006 . t b 02881 . x$

Hamdullah., Lateef, M., A. Maqbool, Abdul Jabbar and M. Abbas et al., 2015. Nematodes infection in different breeds of sheep in balochistan. Pakistan J. Zool., 47: 1077-1082.

Hayajneh, F.M.F., M. Jalal, H. Zakaria, A. Abdelqader and M. Abuajamieh, 2018. Anticoccidial effect of apple cider vinegar on broiler chicken: An organic treatment to measure anti-oxidant effect. Pol. J. Vet. Sci., 21: 361-369.

Hayajneh, F.M., 2018. Anticoccidial effect of ginger and its effects on the antioxidative capacity in broiler chicken, J. Food Agric. Envir., 16: 108-112. DOI: 10.1234/4.2018.5505.

Hoste, H., S. Sotiraki, H. Mejer, F. Heckendorn, V. Maurer and S. Thamsborg, 2014. Alternatives to Synthetic Chemical Antiparasitic Drugs in Organic Livestock Farming in Europe. In: Organic Farming, Prototype for Sustainable Agricultures, Bellon, S. and S. Penvern, (Eds.), Springer Netherlands, Dordrecht, pp: 149-169.

DOI: $10.1007 / 978-94-007-7927-38$

Iqbal, Z., M. Lateef, M.S. Akhtar, M.N. Ghayur and A.H. Gilani, 2006. In vivo anthelmintic activity of ginger against gastrointestinal nematodes of sheep. J. Ethnopharmacol. 106: 285-7. DOI: $10.1016 /$ j.jep.2005.12.031

Jeena, K., V.B. Liju and R. Kuttan, 2013. Antioxidant, anti-inflammatory and Antinociceptive activities of essential oil from ginger. Indian J. Physiol. Pharmacol., 57: 51-62.

Lyndal-Murphy, M., W.K. Ehrlich and D.G. Mayer, 2014. Anthelmintic resistance in ovine gastrointestinal nematodes in inland southern Queensland. AVJ., 11:215-220. DOI: $10.1111 /$ avj. 12250

Nandi, S., M. Saleh-e-In, M. Rahim, N.H. Bhuiyan and N. Sultana et al., 2013. Quality composition and biological significance of the Bangladeshi and China ginger (zingiber officinale). J. Micr. Biotechnol. Food Sci., 2: 2283-2290.

Pena-Espinoza, M., S.M. Thamsborg, J. Demeler and H.L. Enemark, 2014. Field efficacy of four anthelmintics and confirmation of drug-resistant nematodes by controlled efficacy test and pyrosequencing on a sheep and goat farm in Denmark. Vet. Parasitol., 206: 208-215. DOI: 10.1016/j.vetpar.2014.10.017. 
Rahmann, G. and H. Seip, 2006. Alternative strategies to prevent and control endoparasite diseases in organic sheep and goat farming systems-a review of current scientific knowledge, Alternative strategies to prevent and control endoparasite diseases in organic sheep and goat farming, Ressortforschung für den kologischen Landbau,

Rose, H., L. Rinaldi, A. Bosco, F. Mavrot and T. de Waal et al., 2015. Widespread anthelmintic resistance in European farmed ruminants: A systematic review. Vet. Re., 176: 546. DOI: $10.1136 /$ vr.102982.

Sadjjadi, S.M., M.R. Zoharizadeh and M.R. Panjeshahin, 2008. In vitro screening of different Allium sativum extracts on hydatid cysts protoscoleces. J. Invest. Surg., 21: 318-22.

Sanhokwe, M., J. Mupangwa, P.J. Masika, V. Maphosa and V. Muchenje, 2016. Medicinal plants used to control internal and external parasites in goats. O0JVR, 83: a1016-a1016.

DOI: 10.4102/ojvr.v83i1.1016

Sujon, M.A., M. Mostofa, M.S. Jahan, A.R. Das and S. Rob, 2008. Studies on medicinal plants against gastroinstestinal nematodes of goats. Bangl. J. Vet. Med., 6: 179-183. DOI: 10.3329/bjvm.v6i2.2333
Tag el-din, A.E., M.S. Moharam, A.A. Nour and M.E.A. Nasser, 2012. Effect of some herbs on the rumen fermentation: 1-Effect of ginger (zingiber officinale) and garlic (allium sativum) on gas production, energy values, organic matter digestibility and methane emission, in vitro. J. Agric. Env. Sci. Dam. Univ., 11: 33-53.

Urban, J., L. Kokoska, I. Langrova and J. Matejkova, 2008. In vitro anthelmintic effects of medicinal plants used in czech republic. Pharm. Biol., 46: 808-813. DOI: 10.1080/13880200802315618.

Verma, R., K. Lata and G. Das, 2018. An overview of anthelmintic resistance in gastrointestinal nematodes of livestock and its management: India perspectives. Int. J. Chem. Stud., 6: 1755-1762.

Zanini, G.M. and T.C. Graeff, 2001. Inactivation of infective larvae of Angiostrongylys costaricensis with short time incubations in $1.5 \%$ bleach solution, vinegar or saturated cooking salt solution. Acta Tropica, 78: 17-21. 